\title{
There's more to the picture than meets the eye
}

\section{Reply to: Letter to the editor of Acta Neurochirurgica: Blind men and the elephant-comment on "The dentato-rubro-thalamic tract as the potential common deep brain stimulation target for tremor of various origin: an observational case series"}

\author{
Volker A. Coenen ${ }^{1,2} \cdot$ Bastian E. Sajonz ${ }^{1} \cdot$ Marco Reisert $^{1} \cdot$ Horst Urbach $^{3} \cdot$ Peter C. Reinacher $^{1}$
}

Received: 9 April 2020 / Accepted: 13 April 2020 / Published online: 26 April 2020

(C) The Author(s) 2020

We would like to thank Drs. Low and Turner for their thoughtful comments on our paper [1] and their friendly evaluation. We had indeed ourselves early formulated the theory that one fiber tract (DRT(T)) would possibly connect all stereotactic targets for tremor [2-4] ("three stereotactic targets, one anatomical (fiber) structure"). Other authors have looked at this matter and came to slightly different conclusions [5], although — especially for essential tremor - there is a growing literature successfully reporting DRT(T) targeting [6-9]. However, we should not forget that the subthalamic nucleus (STN) itself has clear tremorreducing potency in Parkinson's tremor [10] without a direct involvement of the DRTT and might therefore be an exception to this rule. We have in our workflow implemented DTI guided DRT(T) targeting for most tremor surgery (including Parkinson's disease tremor) since 2011. However, the success of using the DTI technology for targeting depends on good individual imaging, robust reproduction of structures, and flawless tracking strategies. Moreover, neurosurgeons need to be aware of the actual accuracy of this technology which depends on post-processing of imaging and therefore has a certain

This article is part of the Topical Collection on Functional Neurosurgery Movement disorders

Volker A. Coenen

volker.coenen@uniklinik-freiburg.de

1 Department of Stereotactic and Functional Neurosurgery, Medical Faculty of Freiburg University, Freiburg University Medical Center, Freiburg i.Br., Germany

2 Center for Deep Brain Stimulation, Freiburg University Medical Center, Freiburg i.Br., Germany

3 Department of Neuroradiology, Medical Faculty of Freiburg University, Freiburg University Medical Center, Freiburg i.Br., Germany amount of error [11]. This is especially important with respect to the beginning use of DRT(T) targeting in focused ultrasound lesioning procedures [12]. Low and Turner scientifically compared conventional versus DTI-based targeting strategies in their study [13], which is a logical approach [14]. We shoulddespite our enthusiasm-be aware of the slight possibility that the tractographically depicted DRT(T) might just be a surrogate for a yet to be discovered tremor-reducing anatomical structure which at this moment is invisible to our imaging technologies.

Funding Information Open Access funding provided by Projekt DEAL.

Open Access This article is licensed under a Creative Commons Attribution 4.0 International License, which permits use, sharing, adaptation, distribution and reproduction in any medium or format, as long as you give appropriate credit to the original author(s) and the source, provide a link to the Creative Commons licence, and indicate if changes were made. The images or other third party material in this article are included in the article's Creative Commons licence, unless indicated otherwise in a credit line to the material. If material is not included in the article's Creative Commons licence and your intended use is not permitted by statutory regulation or exceeds the permitted use, you will need to obtain permission directly from the copyright holder. To view a copy of this licence, visit http://creativecommons.org/licenses/by/4.0/.

\section{References}

1. Coenen VA, Sajonz B, Prokop T, Reisert M, Piroth T, Urbach H, Jenkner C, Reinacher PC (2020) The dentato-rubro-thalamic tract as the potential common deep brain stimulation target for tremor of various origin: an observational case series. Acta Neurochir 18(20): 130-114

2. Coenen VA, Allert N, Mädler B (2011) A role of diffusion tensor imaging fiber tracking in deep brain stimulation surgery: DBS of the dentato-rubro-thalamic tract (drt) for the treatment of therapy- 
refractory tremor. Acta Neurochir. https://doi.org/10.1007/s00701011-1036-Z

3. Coenen VA, Allert N, Paus S, Kronenbürger M, Urbach H, Mädler B (2014) Modulation of the cerebello-thalamo-cortical network in thalamic deep brain stimulation for tremor. Neurosurgery $75(6)$ : $657-670$

4. Coenen VA, Mädler B, Schiffbauer H, Urbach H, Allert N (2011) Individual fiber anatomy of the subthalamic region revealed with diffusion tensor imaging: a concept to identify the deep brain stimulation target for tremor suppression. Neurosurgery 68(4):10691075 discussion 1075-6

5. Fiechter M, Nowacki A, Oertel MF et al (2017) Deep brain stimulation for tremor: is there a common structure? Stereotact Funct Neurosurg 95(4):243-250

6. Dembek TA, Petry-Schmelzer JN, Reker P et al (2020) PSA and VIM DBS efficiency in essential tremor depends on distance to the dentatorubrothalamic tract. Neuroimage Clin 26:102235

7. Calabrese E (2016) Diffusion tractography in deep brain stimulation surgery: a review. Front Neuroanat 10:1497-1411

8. Sammartino F, Krishna V, Kon Kam King N, Lozano AM, Schwartz ML, Huang Y, Hodaie M (2016) Mov Disord. 31(8): 1217-1225. https://doi.org/10.1002/mds.26633

9. Schlaier J, Anthofer J, Steib K, Fellner C, Rothenfusser E, Brawanski A, Lange M (2015) Deep brain stimulation for essential tremor: targeting the dentato-rubro-thalamic tract? Neuromodulation 18(2):105-112

10. Krack P, Pollak P, Limousin P, Benazzouz A, Benabid AL (1997) Stimulation of subthalamic nucleus alleviates tremor in Parkinson's disease. Lancet 350(9092): 1675
11. Coenen VA, Jenkner C, Honey CR, Madler B (2016) Electrophysiologic validation of diffusion tensor imaging tractography during deep brain stimulation surgery. Am J Neuroradiol:1-9

12. Chazen JL, Sarva H, Stieg PE, Min RJ, Ballon DJ, Pryor KO, Riegelhaupt PM, Kaplitt MG (2018) Clinical improvement associated with targeted interruption of the cerebellothalamic tract following MR-guided focused ultrasound for essential tremor. J Neurosurg 129(2):315-323

13. Low HL, Ismail MNBM, Taqvi A, Deeb J, Fuller C, Misbahuddin A (2019) Comparison of posterior subthalamic area deep brain stimulation for tremor using conventional landmarks versus directly targeting the dentatorubrothalamic tract with tractography. Clin Neurol Neurosurg 185:105466

14. Sajonz BEA, Amtage F, Reinacher PC, Jenkner C, Piroth T, Kätzler J, Urbach H, Coenen VA (2016) Deep brain stimulation for tremor tractographic versus traditional (DISTINCT): study protocol of a randomized controlled feasibility trial. JMIR Res Protoc 5(4):e244 e248

The title of this reply was taken from the song "Hey Hey, My My (into the black)" by Neil Young (1979, Reprise Records).

Publisher's note Springer Nature remains neutral with regard to jurisdictional claims in published maps and institutional affiliations. 